\title{
Anatomy Variation of Ruptured Anterior Communicating Artery (AcoA) Aneurysms : Serial Cases
}

\author{
Muhammad Ari Irsyad ${ }^{1}$, Iskandar Nasution ${ }^{2}$, Muhammad Ihsan Zulkarnain Tala ${ }^{1}$ \\ ${ }^{1}$ Department of Neurosurgery, Universitas Sumatera Utara, Medan, Indonesia \\ ${ }^{2}$ Department of Neurology, Universitas Sumatera Utara, Medan, Indonesia
}

\begin{abstract}
Introduction : Intracranial aneurysms (IA) is an acquired disease characterized by dilatation of intracranial arteries, and is usually found at the location of arterial branches in the cranii base region. The selection of management and anatomic variations is quite interesting to be discussed in the case of aneurysms.

Cases Report : Four cases of AcoA aneurysm were reported with variations in clinical manifestations, A1 segment anatomy, fundal projections and management considerations (Coiling vs. Clipping). This case series illustrates the compatibility with previous case studies that have existed.

Discussion : The author concludes that the actions taken in cases I, II and III are in the form of coiling due to age, dome and neck ratio and access to perform such difficult surgical procedures. In case IV , it was considered to be performed surgical clipping action due to the presence of intracerebal hemoraghic, and the approach can be done from a non dominant hemisphere, proximal control only through the right carotid and the location of the posterior dome which was favorable for surgical clipping

Conclusion : Aneurysms from the ACA-anterior communicating artery (ACoA) complex are some of the most complex lesions in the field of vascular neurosurgery. This location is where most rupture aneurysms occured with high mortalities due to complications of vasospasm and SAH. The choice of management in aneurysm cases which involved many factors such as age and anatomic variations.
\end{abstract}

Keyword: Aneurysm, Vascular, Anatomy, Artery

\section{Introduction}

Intracranial aneurysms (Intracranial Aneurysm, IA) is an acquired disease characterized by dilatation of intracranial arteries, and is usually found at the location of arterial branches in the cranii base region. The formation and rupture of an intracranial aneurysm is a multifactorial event which to date has only identified a number of intrinsic and extrinsic risk factors. [1,2,3]

In the population, the reported incidence was 6 to 10 cases per 100,000 people per year. For unknown reasons, in Finland, Northern Sweden and Japan, the incidence is higher, with 16 to 20 cases per 100,000 people / year. In the neurosurgery department of H. Adam Malik General Hospital, there were 26 cases (18\%) of all cases of intracranial spontaneous bleeding in 2019. [3.4]

*Corresponding author at: Department of Neurosurgery,Universitas Sumatera Utara,Medan, Indonesia

Copyright (C) 2020 Published by Talenta Publisher, ISSN: 2686-0848 ; DOI : 10.32734

Journal Homepage: http://aanhsj.usu.ac.id 
Most aneurysms are found in the anterior circulation $(89 \%$ of those that have ruptured and $90 \%$ of those that have not yet ruptured). The most common locations for intracranial aneurysm rupture were anterior communicating artery (AcoA), 31\%; medial cerebral artery bifurcation (MCAbif), 26\%; and internal carotid arteries at the base of the posterior communicating arteries (ICA-PCoA), 13\%; in the posterior circulation, the location most often in the bifurcation of the basilar artery (BA) 4\%.[5,6,7]

When an intracranial aneurysm ruptured, it will cause subarachnoid hemorrhage (SAH). SAH due to aneurysm is a very severe condition with a cumulative mortality of up to $50 \%$ in 6 months. SAH due to aneurysm cause $5 \%$ to $10 \%$ of strokes, but it is often found at a fairly young age (50-60 years) and is often fatal. This situation caused a decrease in quality of life that is almost the same as that caused by cerebral infarction and intracerebral hemorrhage.[4,8,9]

\section{Cases Report}

This case was taken from medical records at the Department of Neurosurgery, H. Adam Malik General Hospital in 2019. After grouping, the characteristic number of cases of patients with intracranial spontaneous bleeding was found (see Table 1 and Table 2).

The data included in this case report were patients with AcoA aneurysms. Of the 11 patients with ruptured AcoA aneurysms, 4 patients had Digital Subtract Angiography (DSA), while 7 other patients were not performed because the patient's worsening condition or were refusing the procedure.

\section{Case I}

First case, woman, 74 years old,, came to hospital on December, 2019 with complaints thunderclap headache, suddenly since 4 days before admitted to the hospital when the patient was doing light activities (such as taking bath). The patient also complained of projectile vomiting 4 times after the incident. No history of seizures and loss of consciousness was found. There was no history of limb weakness and no history of visual disturbances and respiratory problems were found after the incident. Voiding was withing within normal limits and there was no previous history of smoking and alcohol use. Patients had a history of uncontrolled hypertension since 4 years ago. History of diabetes was not found. 
Table 1. Distribution of Cases of Intracranial Spontaneous Bleeding

\begin{tabular}{|c|c|c|c|}
\hline No & Variable & $\mathbf{n}$ & Percentage (\%) \\
\hline \multirow[t]{3}{*}{1} & Gender & & \\
\hline & - Male & 84 & 57 \\
\hline & - Female & 65 & 43 \\
\hline \multirow[t]{4}{*}{2} & GCS in admission & & \\
\hline & $-\quad 3-4$ & 23 & 15 \\
\hline & $-\quad 5-12$ & 89 & 59 \\
\hline & $-\quad 13-15$ & 38 & 26 \\
\hline \multirow[t]{3}{*}{3} & Age & & \\
\hline & - $\quad<50$ years old & 34 & 23 \\
\hline & - $\quad>50$ years old & 114 & 77 \\
\hline \multirow[t]{5}{*}{4} & Type of Bleeding & & \\
\hline & - Cortical ICH & 14 & 10 \\
\hline & - Subcortical ICH & 107 & 71 \\
\hline & - Aneurysm & 26 & 18 \\
\hline & $-\quad \mathrm{AVM}$ & 2 & 1 \\
\hline \multirow[t]{9}{*}{5} & Location of Bleeding & & \\
\hline & - Frontal & 5 & 3 \\
\hline & - Temporal & 6 & 3 \\
\hline & - Parietal & 2 & 1 \\
\hline & - Occipital & 4 & 3 \\
\hline & - $\quad$ Basal Ganglia & 46 & 31 \\
\hline & - Thalamus & 44 & 30 \\
\hline & - Cerebellum & 9 & 6 \\
\hline & - Brainstem & 7 & 5 \\
\hline \multirow[t]{6}{*}{6} & Aneursym Location* & & \\
\hline & - $\mathrm{MCA}$ & 12 & 48 \\
\hline & - $\quad$ PCOM & 2 & 7 \\
\hline & - ACOM & 11 & 41 \\
\hline & - Basillar & 1 & 4 \\
\hline & Total & 149 & \\
\hline
\end{tabular}

When being admitted to the hospital, the patient was found alert, 15 in glasgow coma scale (GCS) with blood pressure 160/90 mmHg, pulse $102 \mathrm{bpm}$, breathing frequency $20 \mathrm{bpm}$ and temperature $36.8^{\circ} \mathrm{C}$. The pain scale due to the headache was 6-7 according to visual analogue scale (VAS). On neurological examination, there was no meningeal sign and cranial nerve examination was within normal limits. normal motor strength at all four extremities, normal physiological reflexes and no pathological reflexes.

From non contrast Head CT (figure 1), hyperdense lesions was found on the right and left anterior hemispheric fissures and sylvian fissures with a thickness more than 1 slice. The ventricular system is widening with evan's ratio of $25 \%$ and a 
temporal horn $0.5 \mathrm{~cm}$. There were no intraventricular hemoraghic and intracerebral hemoraghic, with a conculusion of subarachnoid hemoraghic with hydrocephalus.

Table 2. Distribution of Aneurysm Cases

\begin{tabular}{|c|c|c|c|c|c|}
\hline No & Variable & $\begin{array}{r}\text { Acom } \\
\text { n(\%) }\end{array}$ & $\begin{array}{c}\text { MCA } \\
\text { n(\%) }\end{array}$ & $\begin{array}{c}\text { PCOM } \\
\text { n(\%) }\end{array}$ & $\begin{array}{c}\text { Basillar } \\
\text { n }(\%)\end{array}$ \\
\hline \multirow[t]{3}{*}{1} & Gender & & & & \\
\hline & - Male & $7(64)$ & $5(42)$ & - & - \\
\hline & - Female & $4(36)$ & $7(58)$ & $2(100)$ & $1(100)$ \\
\hline \multirow[t]{3}{*}{2} & Age & & & & \\
\hline & - $\quad<50$ years old & $3(27)$ & $3(25)$ & - & - \\
\hline & $-\quad>50$ years old & $8(73)$ & $9(75)$ & $2(100)$ & $1(100)$ \\
\hline \multirow[t]{4}{*}{3} & GCS in admission & & & & \\
\hline & $-\quad 3-6$ & $2(18)$ & $2(17)$ & - & - \\
\hline & $-\quad 7-12$ & $5(46)$ & $7(58)$ & $2(100)$ & $1(100)$ \\
\hline & $-\quad 13-15$ & $4(36)$ & $3(25)$ & - & - \\
\hline \multirow[t]{3}{*}{4} & Hydrocephalus & & & & \\
\hline & - Yes & $6(55)$ & $3(23)$ & $1(50)$ & $1(100)$ \\
\hline & - No & $5(45)$ & $9(77)$ & $1(50)$ & - \\
\hline \multirow[t]{5}{*}{5} & Clinical CT Scan & & & & \\
\hline & - $\mathrm{SAH}$ & $1(9)$ & $2(17)$ & $1(50)$ & \\
\hline & $-\quad \mathrm{SAH}+\mathrm{ICH} / \mathrm{IVH}$ & $3(27)$ & $7(58)$ & $1(50)$ & \\
\hline & $-\quad \mathrm{SAH}+\mathrm{ICH}+\mathrm{IVH}$ & $7(64)$ & $3(25)$ & & $1(100)$ \\
\hline & Total & 11 & 12 & 2 & 1 \\
\hline
\end{tabular}
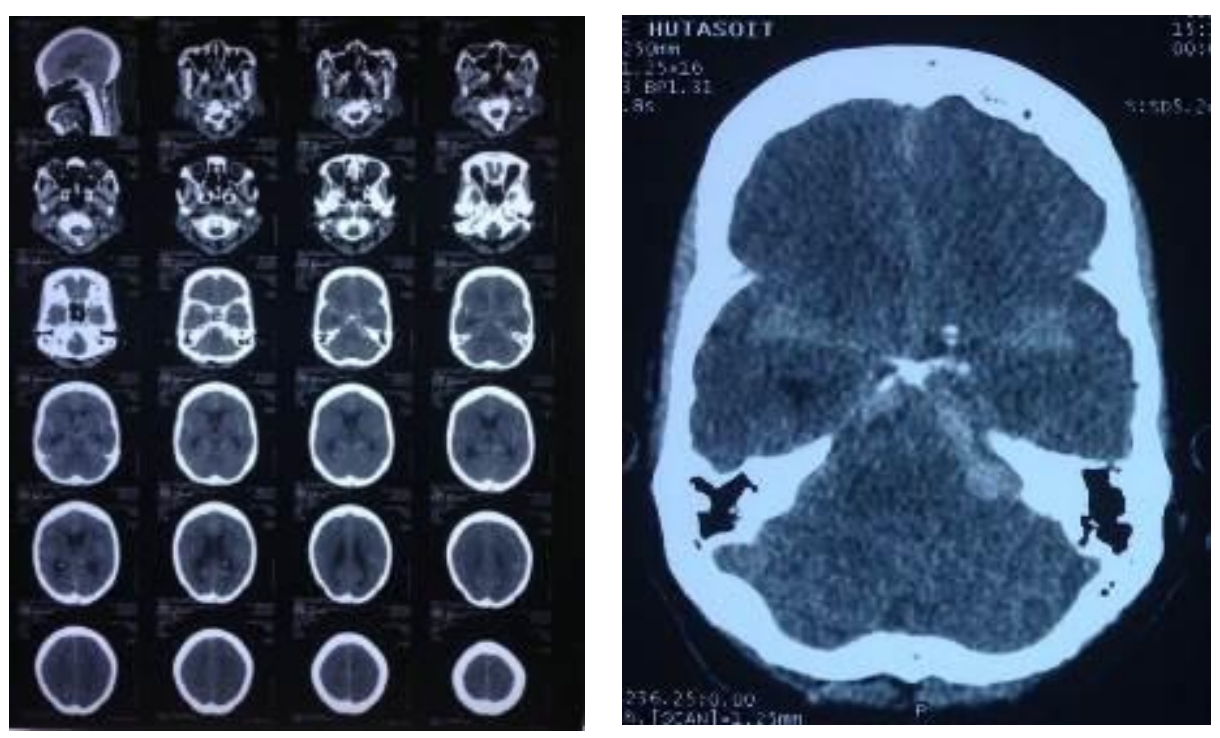

Figure 1. Non Contrast Head CT

DSA examination (figure 2) showed an aneurysm in the anterior communicating artery with a diameter of $\pm 4 \mathrm{~mm}$, sacullar shape, neck to dome ratio $>2: 1$, dome projection towards the antero-inferior sinistra, with no contrast extravasation. 
Contrasting through the right carotid filled the right and posterior MCA segments. Contrasting through the left carotid filled the A2 bilateral segment and the left MCA.
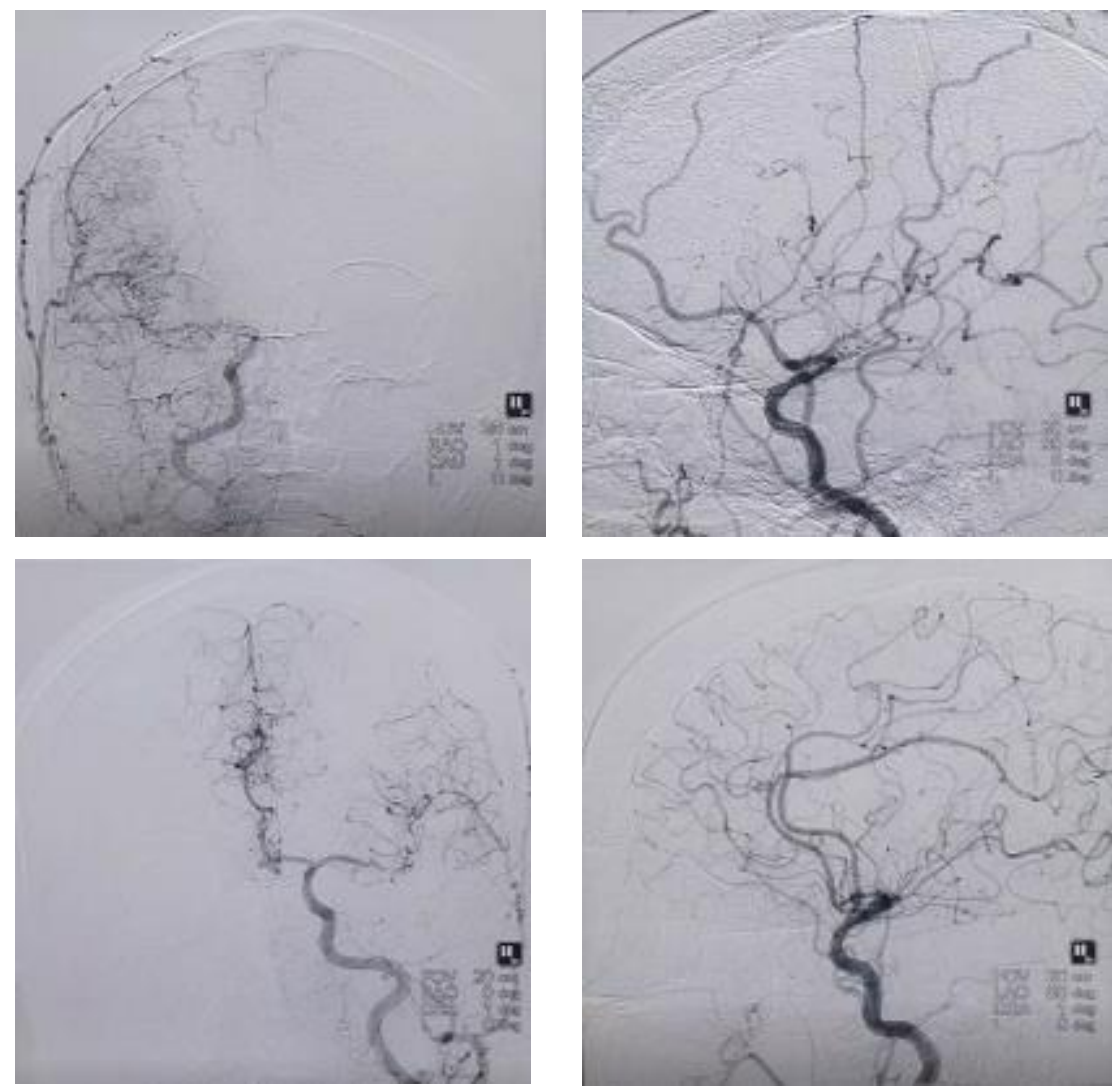

Figure 2. DSA in First Case Patient

This patient was diagnosed with spontaneous subrachnoid hemorrhage caused by rupture of the arterial anterior communicating artery, hydrochepalus with World Federatioan of Neurological Surgery (WFNS) Score 1, Hunt and Hess Score 1, and Fischer grade 3

\section{Case II}

Second case, woman, 57 years old, with the sudden loss of consciousness, since 4 hours before admitted to the hospital. The patient previously complained of severe headache and was followed by a tonic seizure for less than one minute. A history of recurrent headaches experienced by patients since 2 years ago and pain was relieved by analgetics. No history of vomiting was found. Patients had a history of uncontrolled hypertension and diabetes millitus since 5 years ago. There was no history of visual and respiratory disturbance before. Voiding was found within normal limits.

When admitted to the hospital, the patient was somnolent, GCS E3M5V4 with blood pressure of 170/90 $\mathrm{mmHg}$, pulse $110 \mathrm{bpm}$, breathing $20 \mathrm{bpm}$ and temperature of $36.5^{\circ} \mathrm{C}$. On neurological examination, there was no meningeal sign. Cranial nerve and 
motor strength are difficult to be assessed. Physiological reflexes were normal and there was no pathological reflexes. Laboratory tests showed leukocytosis 20,990 uL and hyperglycemia with FBG of 335mg/dl. ECG showed a sinus rhythm. CXR showed CTR $>55 \%$ which was cardiomegaly.

The non contrast Head CT-Scan (figure 3), showed hyperdense lesions on the right and left anterior hemispheric fissures and sylvian fissures with a thickness of more than 1 slice on CT Scan. The ventricular system was normal. There were no signs of intraventricular hemoraghic and intracerebral hemoraghic with a conculusion of subarachnoid hemoraghic.
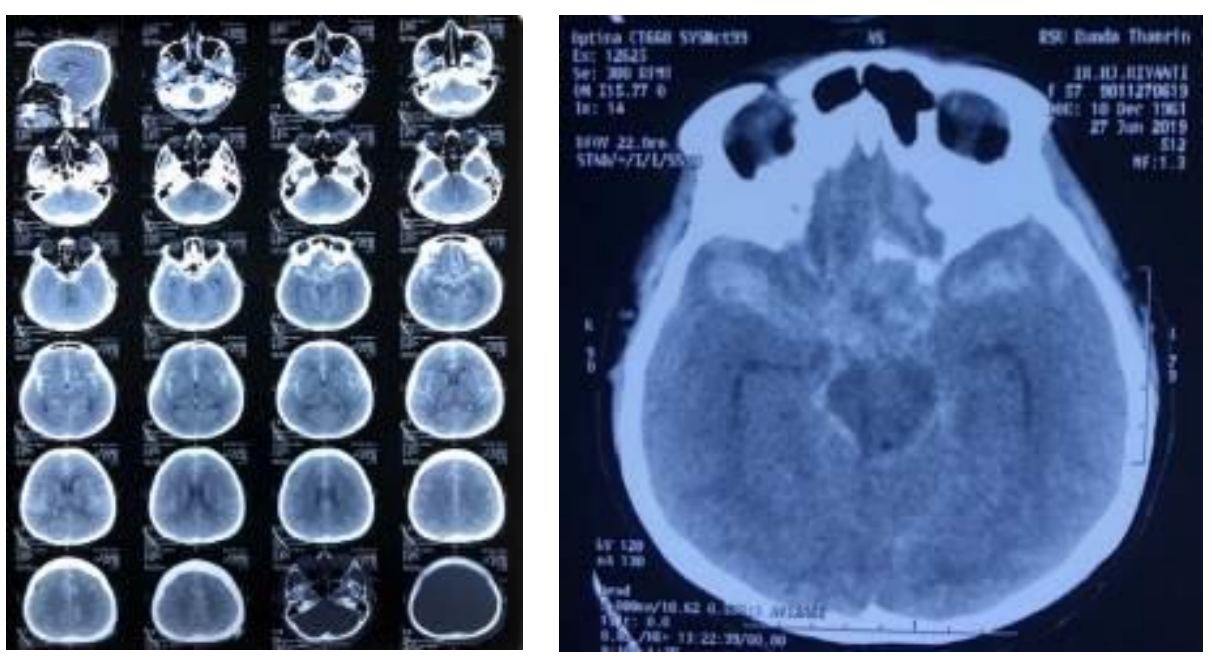

Figure 3. Non Contrast Head CT Second Case

DSA (figure 4) showed an aneurysm in ACoA with a diameter of $\pm 4-5 \mathrm{~mm}$, sacullar shape, neck to dome ratio> 2: 1, dome projection towards the anterior, and no contrast extravasation. Contrasting appears through the internal carotid left filling the left MCA, segment A1 left, aneurysm, segment A2 left and part A2 to right segment.

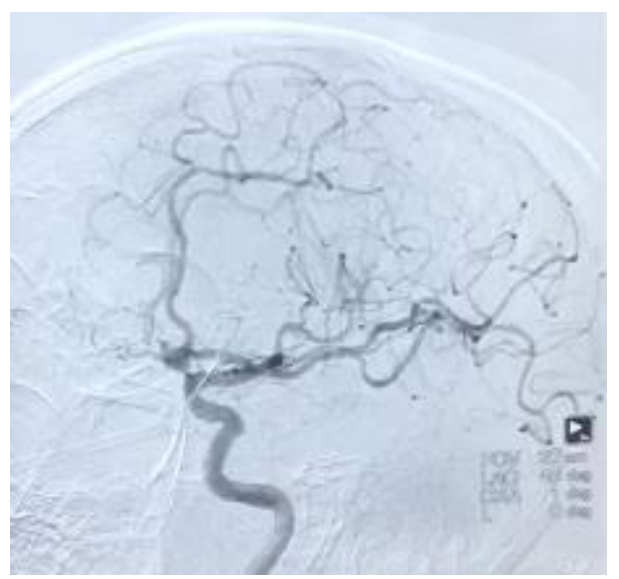

Figure 4. DSA Second Case 
This patient was diagnosed with spontaneous subrachnoid hemorrhage caused by rupture of aneurysm AcoA with WFNS Score 2, Hunt and Hess Score 3, and Fischer grade 3.

\section{Case III}

Third case, woman, 55 years old, was referred to H. Adam Malik General Hospital with complaints of severe thunderclap headaches suddenly experienced by the patient since 1 month ago. There was a history of sudden loss of consciousness experienced shortly after the incident and lasted for approximately 2 weeks. Patients also had a history of projectile vomiting 2 times after the incident. The patient had a tonic seizure and lasts for less than one minute. Patients had a history of uncontrolled hypertension since 5 years ago. There was no history of the use of antiplateletes and herbs or other traditional medicines. The patient was previously treated at the ICU of Takengon Regional General Hospital for approximately 17 days. There was no history of visual impairment and nausea.

When admitted to the hospital, the patient was alert, 15 in GCS, with blood pressure of 140/80 mmHg, pulse $88 \mathrm{bpm}$, breathing $20 \mathrm{bpm}$ and temperature of $36.8^{\circ} \mathrm{C}$. Headache was experienced with a 4-5 VAS pain scale. On neurological examination, there was no meningeal sign and cranial nerves examination was found within normal limits. The patient had normal motoric strength at all extremities, normal physiological reflexes and there was no pathological reflex.

The non contrast Head CT-Scan (figure 5), showed hyperdense lesions on the right and left anterior hemispheric fissures and sylvian fissures with a thickness of more than 1 slice on CT Scan. The ventricular system was widened with an evans ratio of $26 \%$ and a temporal horn of $0.8 \mathrm{~cm}$. There was no intraventricular hemoraghic and intracerebral hemoraghic, with a conculusion of subarachnoid hemoraghic with hydrocephalus

DSA (figure 6) examination showed an aneurysm in the anterior communicating artery with a diameter of $\pm 5-6 \mathrm{~mm}$, sacullar shape, neck to dome ratio $>2: 1$, dome projection towards the anterior, and there was no contrast extravasation. The administration of the contrast from the right carotid fills the A2 segment bilaterally. 

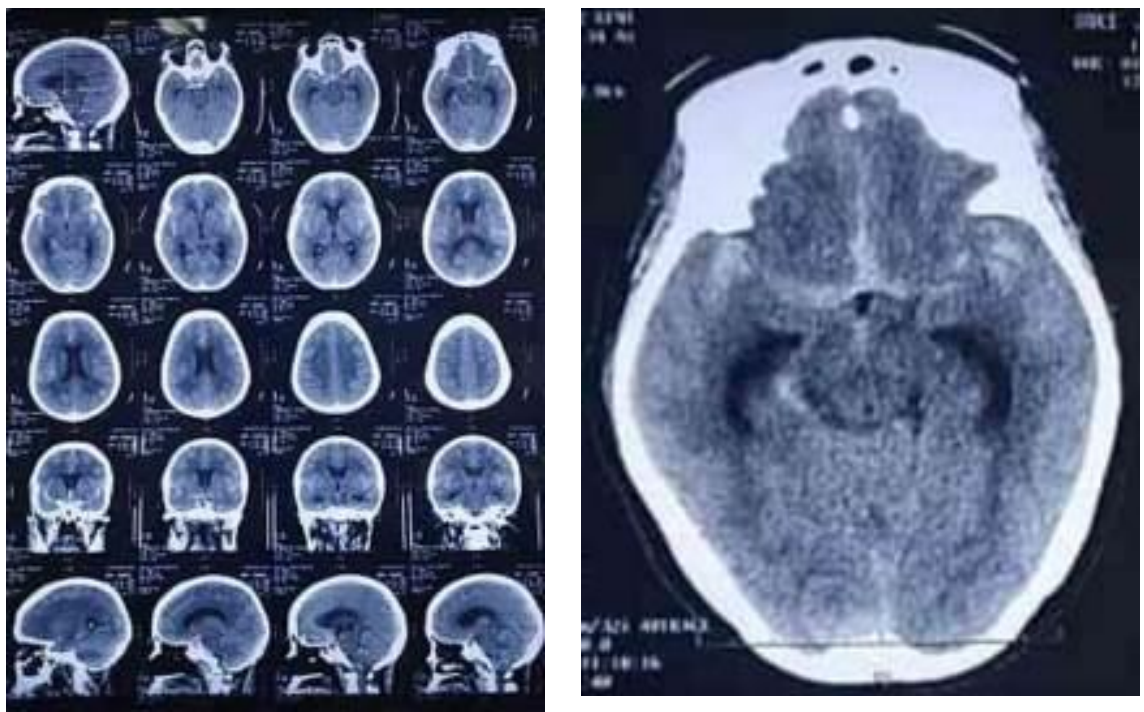

Figure 5 Non Contrast Head CT Scan Case 3
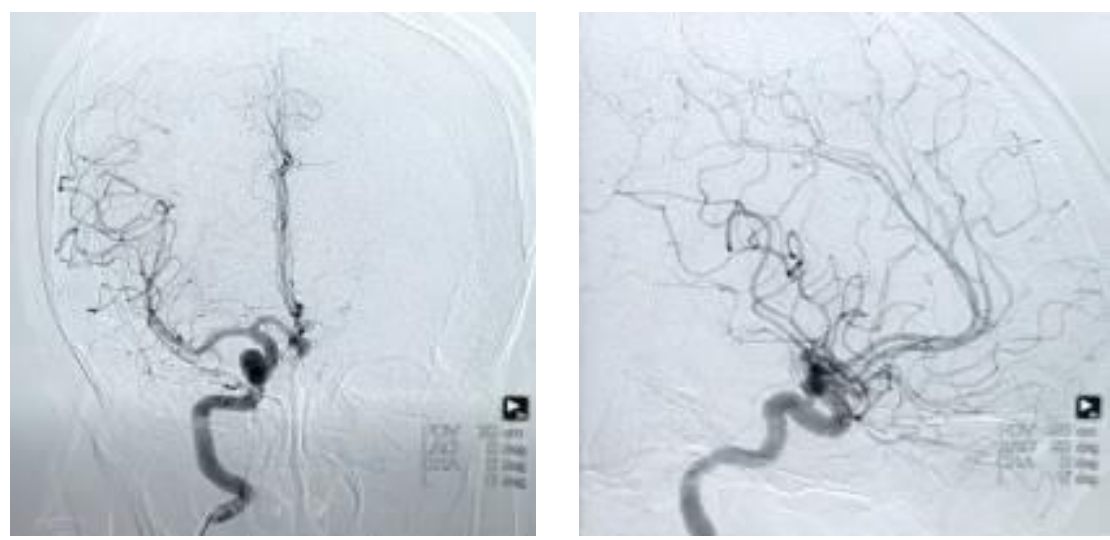

Figure 6 DSA Case 3

This patient was diagnosed with spontaneous subrachnoid hemorrhage caused by rupture of the anterior communicating arterial aneurysm with WFNS Score 1, Hunt and Hess Score 1, and Fischer grade 2

\section{Case IV}

Fourth case, man, 55 years old, with complaints of severe thunderclap headaches experienced by the patient suddenly 1 week before admitted to the hospital. Previously, patients had a history of tonic seizures once, with a duration of less than one minute. Patients with a history of vomiting spurred 5 times after the incident. No history of loss of consciousness and weakness of the limbs were found. The patient had a history of uncontrolled hypertension have not been controlled for 10 years. Blurred eye complaints experienced by patients since the incident. Hormone disorders were not found. 
When admitted to the hospital, the patient was alert (GCS of 15) with blood pressure of 160/90 $\mathrm{mmHg}$, pulse $102 \mathrm{bpm}$, breathing $16 \mathrm{bpm}$ and temperature of $36.2^{\circ} \mathrm{C}$. Headache with a 6-7 VAS pain scale. On neurological examination, there was no meningeal sign and cranial nerves were found within normal limits. All four extremities had normal motor strength, normal physiological reflexes and no pathological reflexes. Eye examination of visus showed 1/6 bilaterally.

The non contrast Head CT-Scan (figure 7), showed hyperdense lesions on the right and left anterior hemispheric fissures and sylvian fissures with a thickness of more than 1 slice on CT Scan. The ventricular system is widened with an evans ratio of $25 \%$ and a temporal horn of $0.5 \mathrm{~cm}$. There are intracerebral hemorrhagic in the frontal area. No intraventricular hemorrhagic was found, with a conculusion of a subarachnoid hemorhage with hydrocephalus plus intracerebral hemorrhagic frontal region
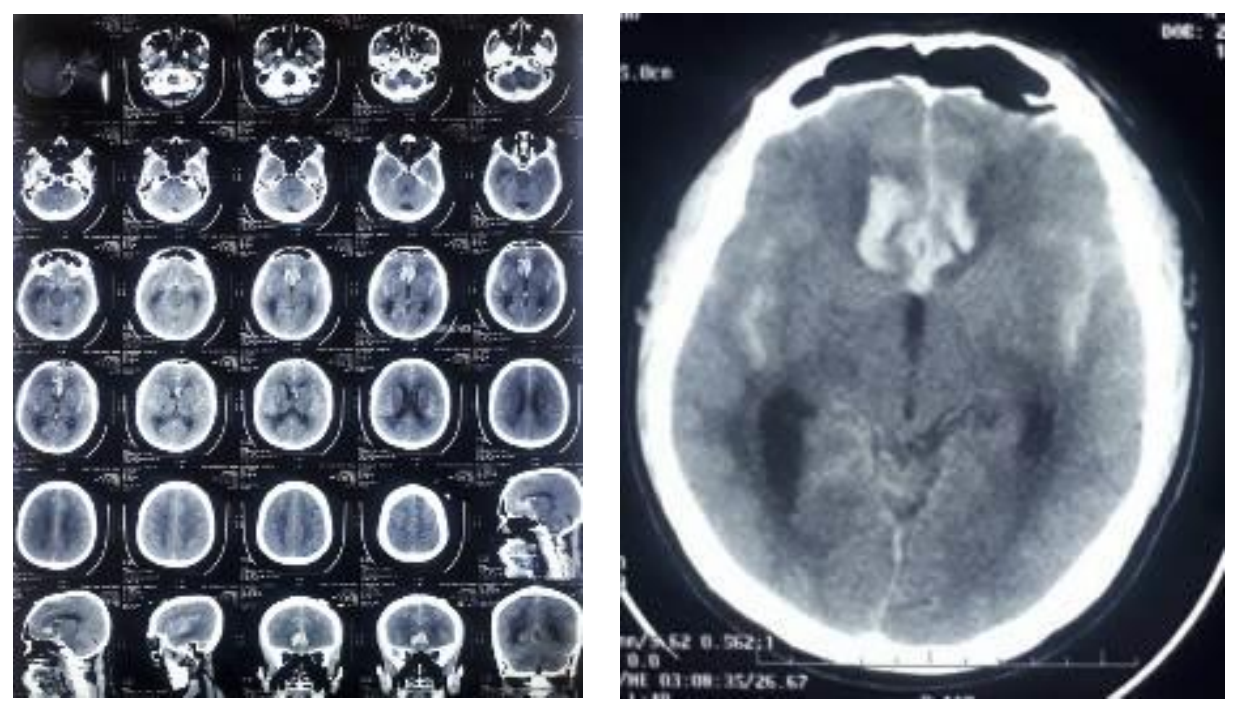

Figure 7. Ctscan Non Contrast Head Case 4

DSA examination (figure 8) showed aneurysm in the anterior communicating artery with a diameter of $\pm 3 \mathrm{~mm}$, sacullar shape, neck to dome ratio> 2 : 1 , dome projection towards the posterior, no contrast extravasation. By providing contrast through the left internal carotid, the contrast fills the left A1 segment to the distal but does not fill the aneurysm sac. 

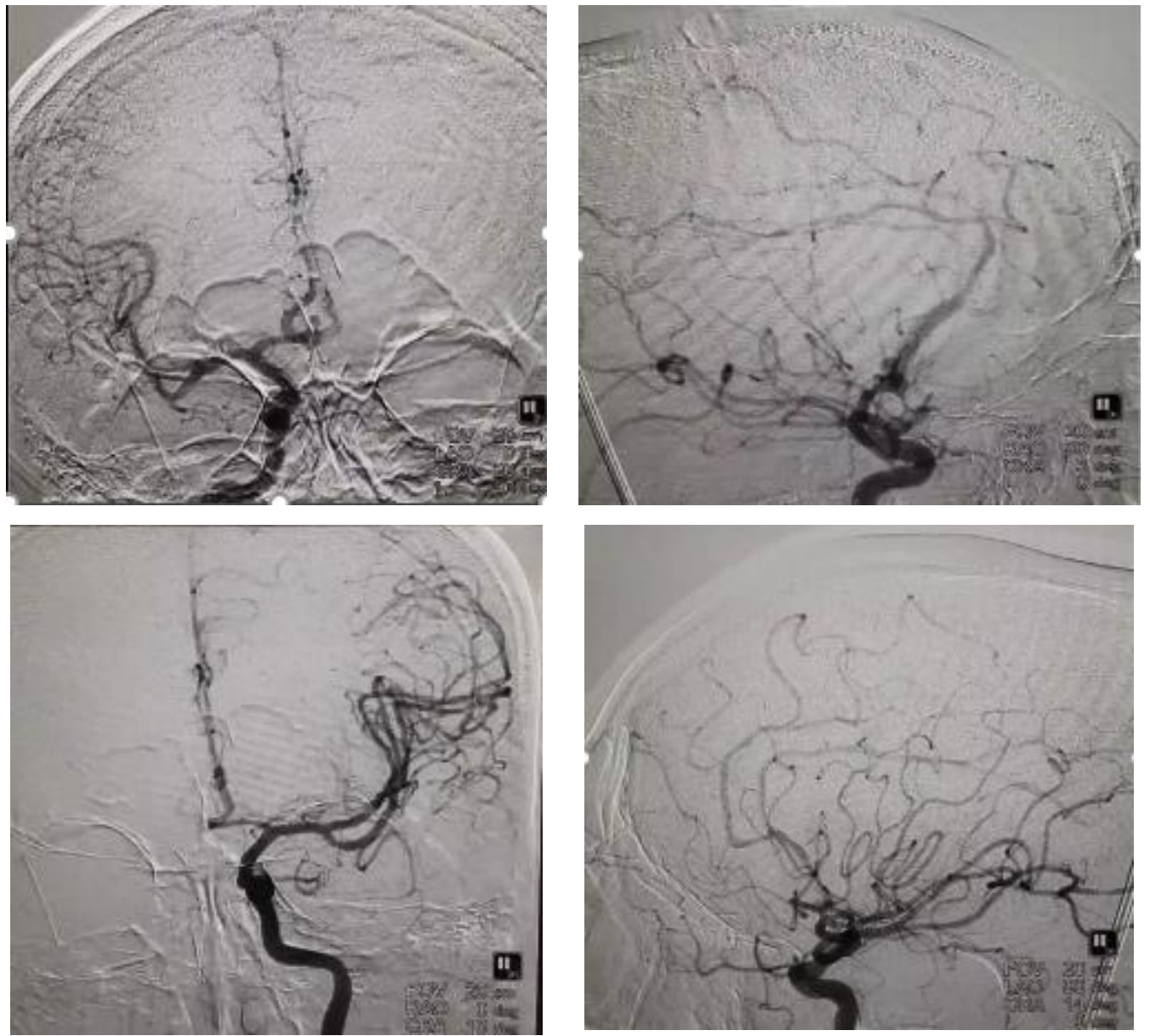

Figure 8 DSA Case 4

This patient was diagnosed with spontaneous subrachnoid hemorrhage caused by rupture of the anterior communicating arterial aneurysm with WFNS Score 1, Hunt and Hess Score 1, and Fischer grade 2.

\section{Discussion}

By the data collected from the medical records in Department of Neurosurgery, H. Adam Malik General Hospital, 2019, there were total of 149 cases of patients with intracranial spontaneous hemorrhage. Among them, 26 patients or $18 \%$ were cases of bleeding due to ruptured aneurysm. The largest distribution of aneurysm locations is MCA (46\%) followed by AcoA and only a few cases of aneurysms occur in PcoA and posterior circulation. Based on the literature, it is known that ACoA is the most frequent place for aneurysms, which is around 375 cases or $37.1 \%$ of the total cases of cerebral aneurysms.[10,11].

Some studies mentioned that aneurysms of AcoA was more common in men than women with an average age of 45.1 years in men and 47.8 in women. In the case of aneurysm incidence rates according to the age of the patient (> 50 years). This is 
consistent with the theory mentioned above, that older age, female sex, smoking, and hypertension increased the risk of IA rupture. The data we collected showed that aneurysms was more common in women (54\%) than men (46\%). However, this number was not enough to represent the global incidence due to the small number of samples.[10,11]

The most dominant clinical manifestation was severe headache in 3 cases (75\%), this is in accordance with the theory mentioned above. One case with a decrease of conciousness $(25 \%)$ as the main complaint. SAH (accounting for about $5 \%$ of all strokes) occurs when an aneurysm, usually located in one of the blood vessels in the Willis circle, ruptures and sheds blood into the subarachnoid space. This blood causes the patient to experience severe headaches and signs of meningeal irritation (neck stiffness or nuchal stiffness, photophobia, and / or positive Kernig signs), as well as changes in the level of consciousness or disturbance of consciousness, seizures, nausea, vomiting, visual disturbances, and / or cranial nerve deficits.[10,11]

Deficits can be classified according to the location of the aneurysm, some of which may arise were visual disturbances due to compression of the optic nerve and optic chiasma, endocrinological / hypothalamic disorders due to hypothalamic artery disorders, paraparesis / hemiparesis, extrapyramidal disorders and psychoorganic disorders. Based on the literatures, there was only $1.1 \%$ of cases of AcoA aneurysm rupture caused symptoms of neurological deficits.[10,11]

Anatomy studies through CT imaging angiography and dynamics of perfusion of blood flow through DSA investigations are important before deciding on the definitive management in either endovascular, microsurgery or the combination of both of them. For example, the choice of the procedure in an open microsurgery depends on the dominance of A1 segments for proximal control in operations.

In the literature mentioned that the presence of Acom aneurysms was associated with wider bifurcation angles, and this suggested that there might exist correlation between the ACA bifurcation geometry and the morphology of Acom aneurysms.[12] Our reports revealed that the size of the aneurysm correlated significantly with the diameter of the Acom, A1 and A2 artery. Furthermore, a positive correlation was observed between the neck width of the aneurysm and the diameter of the blood vessels. When there was hypoplasia in one of the A1 segment in the case of an AcoA aneurysm, the blood supply for the ipsilateral medial hemisphere is obtained from the contralateral internal carotid artery. In this variation, the largest A1 segment diameter can be 
considered as the main branch that will supply bilateral segments A2 and ACoA aneurysms. [10, 11,12]. Variations and occurrence rates can be seen in the figure 9 [13]

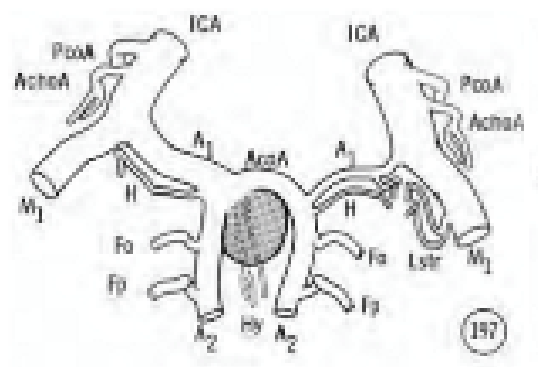

A

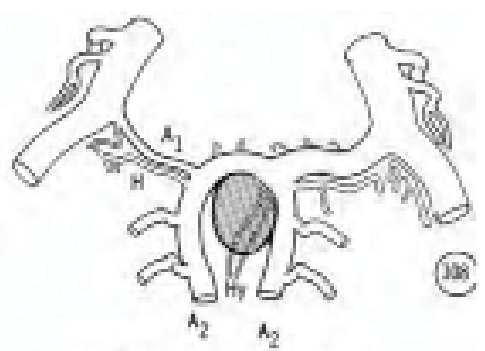

$\mathrm{B}$

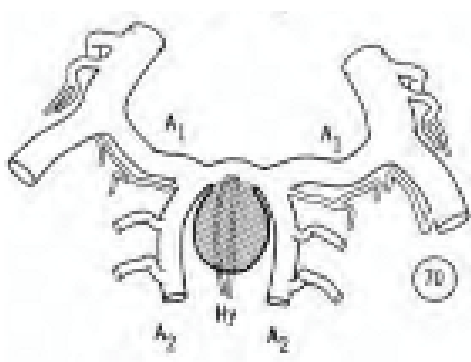

$\mathrm{C}$

Figure 9 Schematic difference in position from AcoA to A1 segment. The number circled is the number of cases from each variation.

In this report, a case of AcoA aneurysm (Case 1) is shown with the main branch of A1 sinistra segment and aplasia (total obstruction) of A1 dextra. From previous studies, the number of variations of this type ranges from 5 (1.3\%) of a total of 375 AcoA aneurysms. 197 cases (52.5\%) of AcoA aneurysms originated from the left segment A1 junction and AcoA, 108 cases (28.8\%) originated from the right segment A1 junction and AcoA. Only 70 cases (18.7\%) of aneurysms originated from midline AcoA

Another anatomic variation that may occur is the persistence of the AcoA anomaly. Embryologically, AcoA originates from multivascular merging into a main structure connecting A1 segments left and right. When the coalescence process was not perfect, several vascular bridges will be forming persistent primitive vascular. Schematic representation of various anatomical variations of the AcoA analysis can be seen in the figure 10 [13].

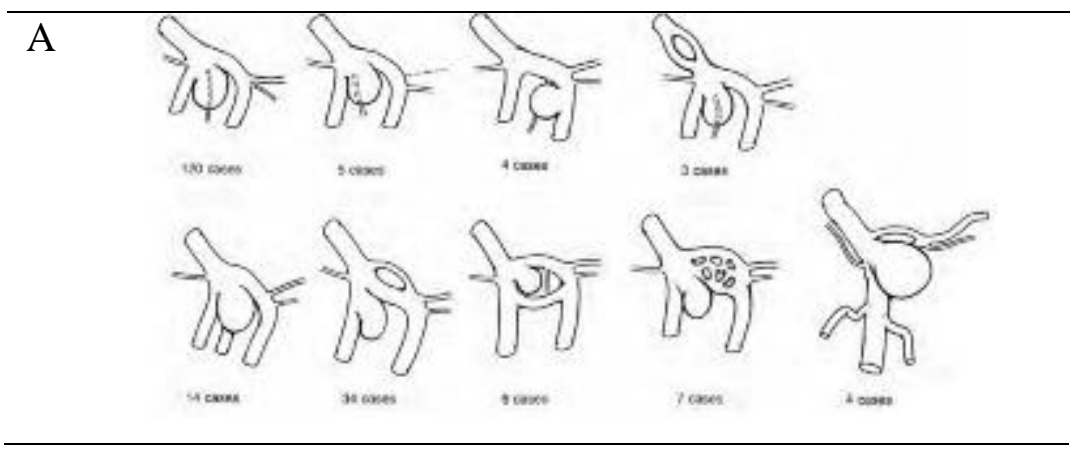




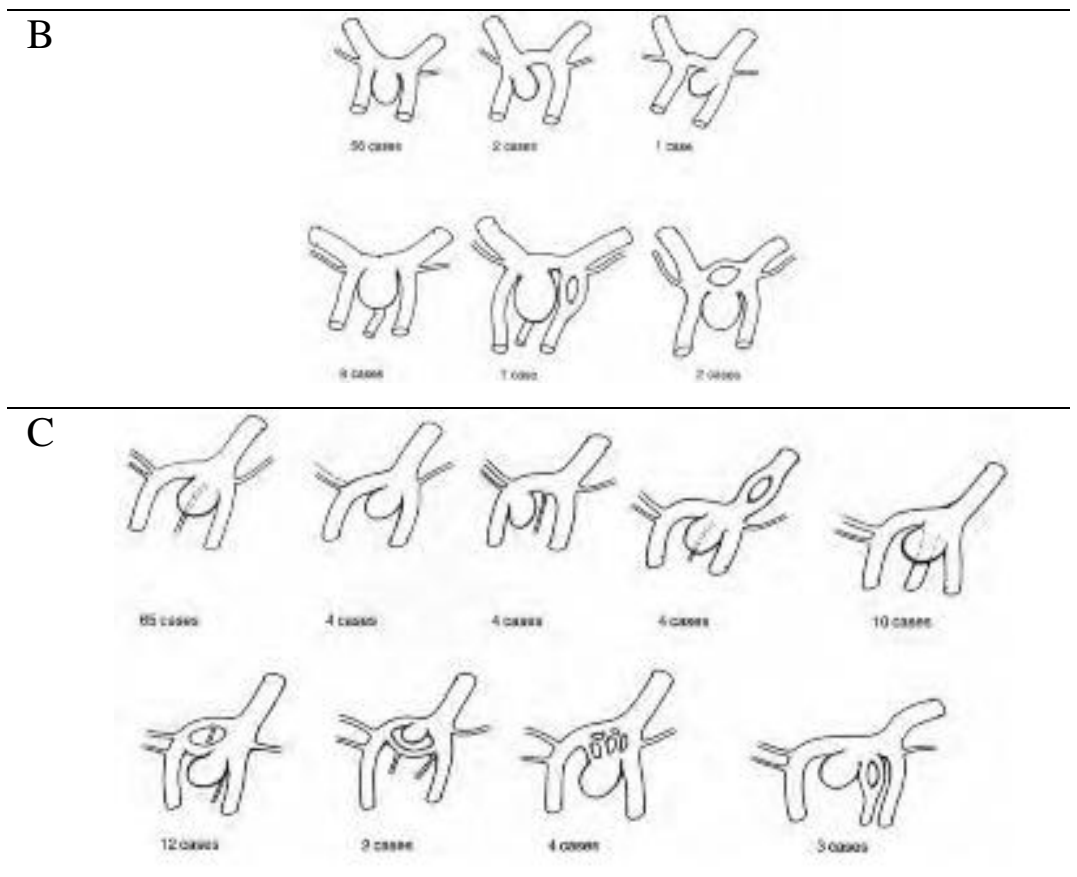

Figure 10 Schematic representation of various anatomical variations of AcoA aneursima with hypoplasia A1 dextra (A), Equal A1 (B) and hypoplasia A1 sinistra (C)

The course of the fundus aneurysm is important in preparing dissection in microsurgery technique. Based on the literature there were 4 main positions of fundus aneurysms while the complex category was a combination of some of these positions (figure 11 and 12). [13]
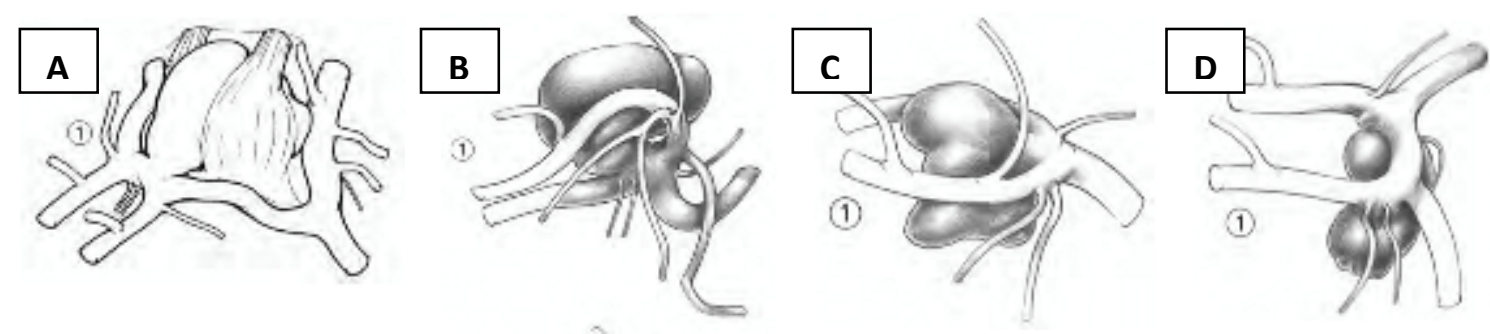

Figure 11 Projection of an AcoA aneurysm (A) Anterior (B) Superior (C) Posterior (D) Inferior

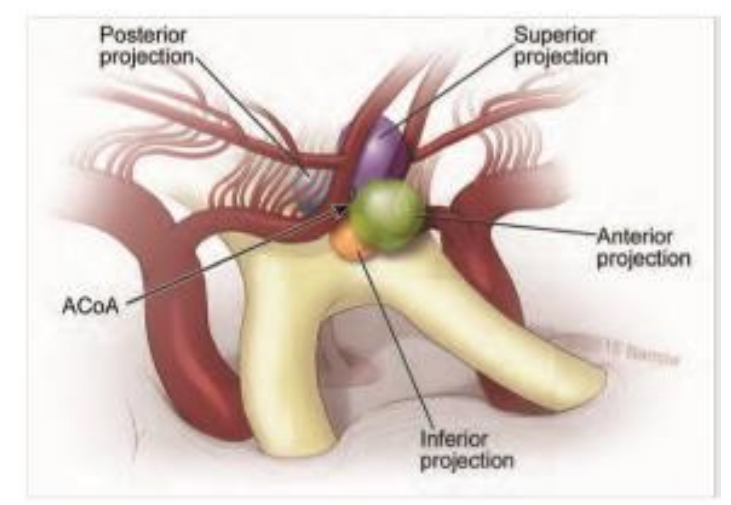

Figure 12. Illustration of AcoA aneurysm projection 
In the literature, the highest percentage of fundus projection course was posterior projections $(34.4 \%)$ followed by superior projections $(22.7 \%)$, inferior projections $(14.1 \%)$ and anterior projections $(12.8 \%)$. On the posterior projection, the aneurysm covers the contralateral A2 segment and the base of the frontoorbital and frontopolar arteries. Superior projection is the most favorable position for neurosurgeons because the fundus is immediately visible when dissecting, whereas inferior projection is the most difficult position because the aneurysm is behind the terminal lamina. Aneurysm enlargement anteriorly can suppress the chiasma and pituitary stalk, so that in the size of an aneurysm large symptoms of vision and hormonal disorders may appear.

\section{Conclusion}

IA are acquired diseases that are marked by intracranial artery dilatation, and are usually found in the artery branching location near the base of the skull. The formation and rupture of an intracranial aneurysm is a multifactorial event which to date has only identified a number of intrinsic and extrinsic risk factors. Aneurysms from the ACAACoA complex are some of the most complex lesions in the field of vascular neurosurgery. This location is where most rupture aneurysms occur with high mortalitis due to complications of vasospasm and $\mathrm{SAH}$

In the case study of aneurysm rupture in the Department of Neurosurgery in 2019, the incidence rate (sex and risk factor) was found to be consistent with previous studies, but not the age incidence rate. This may be because the small amount of data, so it cannot describe an equivalent relationship with previous studies. 4 cases of AcoA aneurysm have been shown with variations in clinical manifestations, A1 segment anatomy, fundus projections and management considerations (Coiling vs. Clipping). This case series illustrates the compatibility with previous case studies that have existed.

Based on the discussion of the procedure, the authors conclude the procedures taken in cases I, II and III in the form of coiling due to age, dome and neck ratio and access to achieve difficult surgical procedures. In case IV, it is considered to perform surgical clipping action due to the existence of intracerebal hemorhage, and the approach can be done from a non dominant hemisphere, proximal control only through the right carotid and the location of the posterior dome which was favorable for surgical clipping. Besides DSA, CTA examination is still necessary to provide a detailed description of the aneurysm's morphology and anatomy. This examination could help predicting the success of endovascular or cliping treatment. 


\section{References}

[1] Hop JW, Rinkel GJ, Algra A, van Gijn J. Case-fatality rates and functional outcome after subarachnoid hemorrhage: a systematic review. Stroke 1997;28:660-664

[2] Fogelholm R, Hernesniemi J, Vapalahti M. Impact of early surgery on outcome after aneurysmal subarachnoid hemorrhage. A population-based study. Stroke 1993;24:1649-1654

[3] Frösen J, Piippo A, Paetau A, et al. Remodeling of saccular cerebral artery aneurysm wall is associated with rupture: histological analysis of 24 unruptured and 42 ruptured cases. Stroke 2004;35:2287-2293

[4] Vlak MH, Algra A, Brandenburg R, Rinkel GJ. Prevalence of unruptured intracranial aneurysms, with emphasis on sex, age, comorbidity, country, and time period: a systematic review and meta-analysis. Lancet Neurol 2011;10:626-636

[5] Frösen J, Tulamo R, Paetau A, et al. Saccular intracranial aneurysm: pathology and mechanisms. Acta Neuropathol 2012;123:773-786

[6] Tulamo R, Frösen J, Junnikkala S, et al. Complement activation associates with saccular cerebral artery aneurysm wall degeneration and rupture. Neurosurgery 2006;59:1069-1076, discussion 1076-1077

[7] Rinkel GJ, Djibuti M, Algra A, van Gijn J. Prevalence and risk of rupture of intracranial aneurysms: a systematic review. Stroke 1998;29:251-256

[8] Juvela S, Poussa K, Porras M. Factors affecting formation and growth of intracranial aneurysms: a long-term follow-up study. Stroke 2001;32: 485-491

[9] Feigin VL, Rinkel GJ, Lawes CM, et al. Risk factors for subarachnoid hemorrhage: an updated systematic review of epidemiological studies. Stroke 2005;36:2773-2780

[10] Korja M, Silventoinen K, McCarron P, et al; Genome in Project. Genetic epidemiology of spontaneous subarachnoid hemorrhage: Nordic Twin Study. Stroke 2010;41:2458-2462

[11] Bor AS, Rinkel GJ, Adam IJ, et al. Risk of subarachnoid haemorrhage according to number of affected relatives: a population based case-control study. Brain 2008;131(Pt 10):2662-2665

[12] Castilla, L.R, Nakaji, Peter. Siddiqui, Adnan. Spetzler, Robert. Decision Making in Neurovascular Disease : Anterior Communicating Artery Aneurysms. 2018.189-196 
[13] Yasargil, M.G. Clinical Considerations, Surgery of Intercranial Aneurysms and Results.Thieme Stratton.1984: 169-185 